\title{
EL MACROZOOBENTOS DE FONDO BLANDO FRENTE A LA BAHÍA DE CATARINDO DURANTE EL FENÓMENO "EL NIÑO 1997-98"
}

\author{
THE SOFT BOTTOM MACROZOOBENTHOS IN FRONT OF CATARINDO BAY \\ DURING "EL NIÑO 1997-98""
}

Pastor Coayla*

\section{RESUMEN}

Se analizó los cambios del macrozoobentos durante el período enero de 1997 a julio de 1998 en la estación fija de Catarindo (Mollendo - Arequipa), ubicada en los $17^{\circ} 011^{\prime 1} 13^{\prime \prime}$ LS y $72^{\circ} 02^{\prime} 19^{\prime \prime}$ LW. Las muestras fueron tomadas con una draga van Veen de $0,04 \mathrm{~m}^{2}$, a 34 metros de profundidad. Se registró un total de 50 especies diferentes, correspondientes a poliquetos, moluscos, crustáceos y otros; observándose en 1998 un incremento de especies de moluscos y crustáceos que no estuvieron presentes en 1997. Durante "El Niño 1997-98", predominaron numéricamente el grupo de los poliquetos, siendo las especies más importantes Prionospio peruana, Nephtys multicirrata, Goniada sp., y Leitoscoloplos chilensis. La mayor densidad del macrozoobentos se registró en la primavera de 1997 y parte del verano de 1998, siendo P. peruana la de mayor densidad. La biomasa durante 1997 se presentó fluctuante y la mayor fue aportada por el grupo de los poliquetos, en tanto que en 1998 el incremento de la biomasa fue dada principalmente por los moluscos. La diversidad presentó valores entre 1,5 y 3,2 bits, los mayores valores fueron registrados durante el verano e invierno de 1997 y a finales del verano e inicios del otoño de 1998.

Palabras claves: Macrozoobentos, fondo blando, El Niño, Bahia de Catarindo, Mollendo.

\begin{abstract}
The changes in macrozoobenthos were analyzed during January of 1997 to July of 1998 in Catarindo station (Mollendo-Arequipa) located at $17^{\circ} 01^{\prime} 13^{\prime \prime} \mathrm{LS}$ and $72^{\circ} 02^{\prime} 19^{\prime \prime} \mathrm{LW}$. The samples were analyzed with a van Veen dredge of $0,04 \mathrm{~m}^{2}$ to $34 \mathrm{~m}$ depth. A total of 50 different species, correspond to polychaete, mollusks, crustacean and others, were recorded; there were an increase of mollusks and crustacean species in 1998 which were absent in 1997. During "El Niño 1997-98" polychaete towered over numerically, being the most important species Prionospio peruana, Nephtys multicirrata, Goniada sp. and Leitoscoloplos chilensis. The major macrozoobenthos density was recorded in spring of 1997, and part of summer 1998, corresponding to $P$. peruana. The biomass fluctuated and the highest value corresponded to the polychaete group in 1997, but in 1998, the biomass increase corresponded to mollusk group. The diversity presented values ranged between 1,5 and 3,2 bits, the highest values were recorded during summer and winter of 1997 and at the end of summer and beginning of autumn 1998.
\end{abstract}

Key words: Macrozoobenthos, soft bottorn, El Niño, Catarindo Bay, Mollendo.

\section{INTRODUCCIÓN}

El fenómeno "El Niño" (EN), no sólo afecta al clima de una región, sino que además, produce una alteración en el ecosistema

* Instituto de Investigación y Desarrollo Hidrobiológico (INDEHI) - Univ. Nac. de San Agustín. Casilla 207, Mollendo-Perú.

E-mail: indehi@unsa.edu.pe marino, con efectos en los recursos marinos, reflejados en sus procesos fisiológicos, con los consiguientes cambios de biomasa y densidad poblacional.

Las investigaciones efectuadas sobre los efectos negativos de EN, generalmente hacen pensar que es común en todo el bentos submareal. Sin embargo, los pocos estudios efectuados sobre la macrofauna de fondo 
blando están demostrando que EN tiene un efecto favorable para el macrozoobentos de fondo blando que habita en áreas de mínimo oxígeno (Tarazona et al., 1985).

El presente trabajo trata sobre los cambios producidos en el macrozoobentos de fondo blando frente a la bahía de Catarindo durante EN 1997-98.

\section{MATERIAL Y MÉTODOS}

El estudio del macrozoobentos submareal de fondo blando, se realizó en una estación de muestreo a 34 metros de profundidad frente a la bahía de Catarindo, ubicada en los $17^{\circ} 01^{\prime} 13^{\prime \prime}$ LS y 72002'19" LW (Fig. 1). Los muestreos cuantitativos fueron realizados entre enero de 1997 y julio de 1998. En la obtención de las muestras, se empleó una draga tipo van Veen de $0,04 \mathrm{~m}^{2}$ y se tomó como máximo 4 réplicas positivas por muestreo, el sedimento obtenido fue tamizado con una malla de $0,5 \mathrm{~mm}$ de apertura, ésta retiene el material biológico que luego es fijado en formol al $10 \%$ para su posterior análisis; y además se tomó la tempcratura del agua de mar en superficie y fondo. En el laboratorio, las muestras fueron analizadas cuantitativamente, procediendo a separar los organismos bentónicos, hasta el taxón más bajo posible, a fin de tener la composición por especies, y los valores promedios de densidad y biomasa húmeda. El índice de diversidad de Shannon y Wiener fue calculado de acuerdo a la fórmula $H^{\prime}=\sum$ pi $\log _{2}$ pi.

\section{RESULTADOS}

\section{La temperatura}

La temperatura superficial del mar (TSM) entre enero de 1997 y julio de 1998 (Fig. 2), presentó valores que estuvieron por encima del promedio patrón (1987-1996) de la estación fija de Catarindo, incrementándose considerablemente a partir de abril de 1997, alcanzando anomalías de $3,7^{\circ} \mathrm{C}$ en agosto de 1997 y de 4,9 en enero de 1998. El comportamiento de la temperatura a $34 \mathrm{~m}$ de profundidad fie similar al presentado en la superficie, con valores de temperatura que fluctuaron entre $13,8^{\circ} \mathrm{C}$ en marzo de 1997 y 21,9 en enero de 1998.

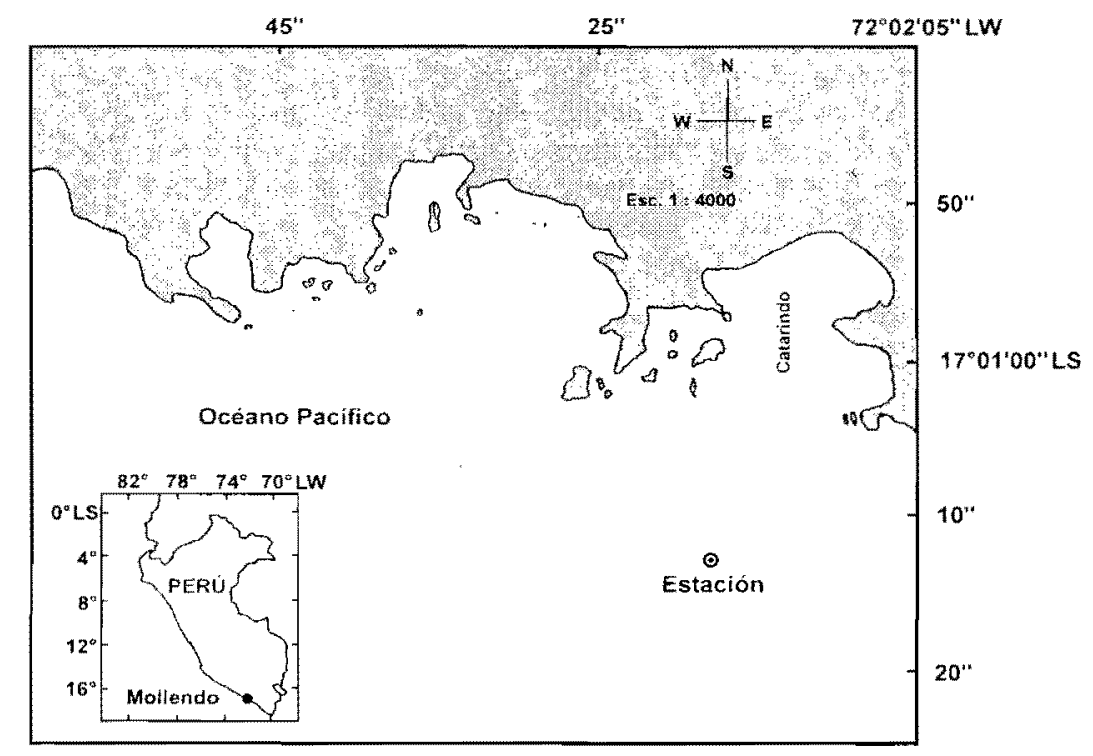

Figura 1. Ubicación de la zona de estudio. Bahía Catarindo, Mollendo, Arequipa. 


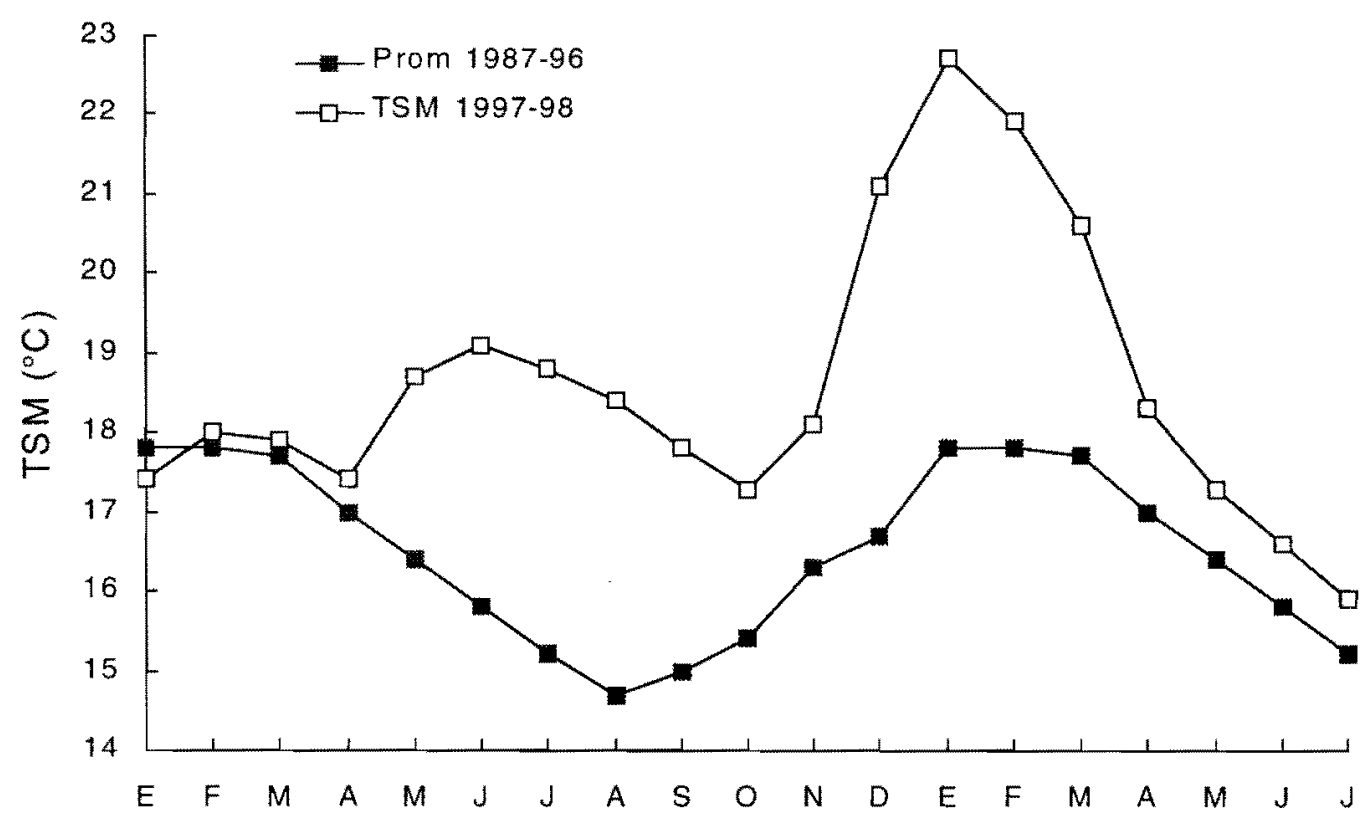

Figura 2. Fluctuaciones de la temperatura superficial del mar (TSM) durante "El Niño 199798 " en Catarindo, Mollendo.

\section{EI macrozoobentos}

Durante el período de 1997-1998 se registró un total de 50 especies diferentes (Tab. 1), el mayor porcentaje (46\%) correspondió al grupo de los poliquetos seguido en importancia por los moluscos, crustáceos y el grupo otros; constituyéndose como las especies más importantes Prionospio peruana, Aricidea sp., Nephtys multicirrata y Leitoscoloplos chilensis. En 1998, se registró la presencia de un mayor número de especies y la ausencia de los poliquetos Magelona sp., Typosyllis sp. y Pectinaria sp.

La densidad media total del macrozoobentos fue de 2106,5 ind $\times 0,04 \mathrm{~m}^{-2}$, con un promedio de 150 por mes, presentando valores que fluctuaron entre 360,5 a 49,3 ind $\times 0,04 \mathrm{~m}^{-2}$ correspondientes a los meses de octubre de 1997 y abril de 1998 respectivamente (Fig. 3), observándose un incremento de la densidad de marzo a octubre de 1997, para posteriormente comenzar a disminuir hasta abril de 1998, y luego mantenerse en densidades por debajo de los 160 ind. $\times 0,04 \mathrm{~m}^{-2}$.

Durante el fenómeno EN, se observó una dominancia de los poliquetos sobre los demás grupos taxonómicos; estacionalmente la densidad media por taxones (Fig. 4) muestra un incremento notorio en primavera de 1997 , donde la mayor densidad correspondió al poliqueto $P$. peruana, presentando otros incrementos de menor grado durante el otoño de 1997 y el verano 1998 (151 y 156,8 ind. $\times 0,04 \mathrm{~m}^{-2}$ respectivamente), destacando siempre la dominancia de $P$. peruana en ambos períodos estacionales. Mientras que en 1998 se incrementó considerablemente la densidad del poliqueto Aricidea sp., y posteriormente se constituyó en la especie dominante durante el otoño e invierno de 1998. Los moluscos presentaron densidades más o menos uniformes durante todo el período, siendo Mysella roqueforti la especie numéricamente dominante, excepto durante el otoño e invierno de 1998 donde la mayor dominancia correspondió a los moluscos Polinices sp. y Nassarius gayi respectivamente. El grupo de los crustáceos, tuvo incrementos similares producidos durante el verano, invierno y primavera de 1997 (27,3; 29,6 y 27 ind. $\times 0,04 \mathrm{~m}^{-2}$ respectivamente), se 
Tabla 1. Composición del macrozoobentos durante "El Niño 1997-98" en Catarindo, Mollendo.

\begin{tabular}{lcc}
\hline Especies & 1997 & 1998 \\
\hline Poliquetos & $*$ & $*$ \\
Aricidea sp. & $*$ & $*$ \\
Nepthys multicirrata & $*$ & $*$ \\
Goniada sp. & $*$ & $*$ \\
Parandalia fauveli & $*$ & $*$ \\
Prionospio peruana & $*$ & $*$ \\
Glycera americana & $*$ & \\
Magelona sp. & $*$ & $*$ \\
Lumbrineris sp. & $*$ & $*$ \\
Sthenelais koepkei & $*$ & $*$ \\
Pilargis sp. & $*$ & $*$ \\
Leitoscoloplos chilensis & $*$ & \\
Typosyllis sp. & $*$ & $*$ \\
Ancystrocillis sp. & $*$ & $*$ \\
Sigambra bassi & $*$ & \\
Pectinaria sp. & $*$ \\
Diopatra sp. & $*$ \\
Axiotella sp. & $*$ \\
Onuphidae & & $*$ \\
Microspio sp. & $*$ \\
Chaetozone sp. & & $*$ \\
Shyllodocidae & & $*$ \\
Poliqueto n.i. & & $*$ \\
Moluscos & & $*$ \\
Oliva peruviana & & $*$ \\
Mysella roqueforti & & \\
Nassarius gayi & & \\
\hline & & \\
\hline
\end{tabular}

: no identificado

destacando la dominancia de los Amphipoda y en segundo lugar Cumacea sp. (Fig. 4).

En general, la biomasa media total del macrozoobentos fue mayor en 1998 (segunda fase $E N$ ), por un mayor aporte de biomasa de las especies Oliva peruviana, N. gayi, Natica sp., Glycera americana y el ofiuroideo Ophiactis kröyeri; en cambio, en 1997 (primera fase EN) el mayor aporte de biomasa fue de los poliquetos $N$. multicirrata y $G$. americana. La biomasa media durante EN, presentó valores que fluctuaron entre 0,16 (agosto de 1997) y $2,6 \mathrm{~g} \times 0,04 \mathrm{~m}^{2}$ (julio de 1998), con un promedio de 0,67 biomasa mensual (Fig. 5).

Estacionalmente la biomasa media por

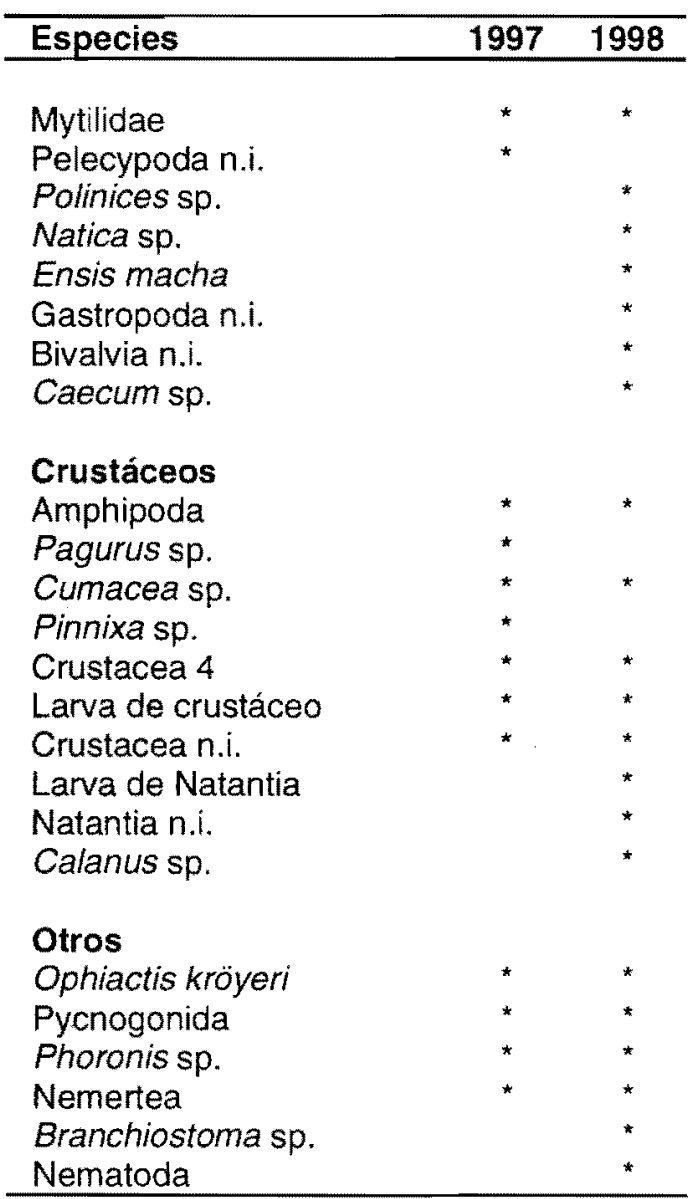

grupos taxonómicos (Fig. 6), mostró que los poliquetos presentaron poca variación durante “El Niño 1997-98”, sin embargo, se apreció un ligero incremento de la biomasa durante la primavera de 1997 y en el verano e invierno de 1998 , donde los poliquetos $G$. americana y $P$. peruana fueron los que aportaron la mayor biomasa. Los moluscos, en la mayoría de los períodos estacionales, presentaron bajos valores de biomasa, excepto durante el verano y el invierno de 1998 en que se incrementó considerablemente la biomasa del grupo $(0,35$ y $0,5 \mathrm{~g} \times 0,04 \mathrm{~m}^{-2}$ respectivamente), debido principalmente al peso aportado por los moluscos $O$. peruviana y $N$. gayi. Los crustáceos mantuvieron valores de biomasa 


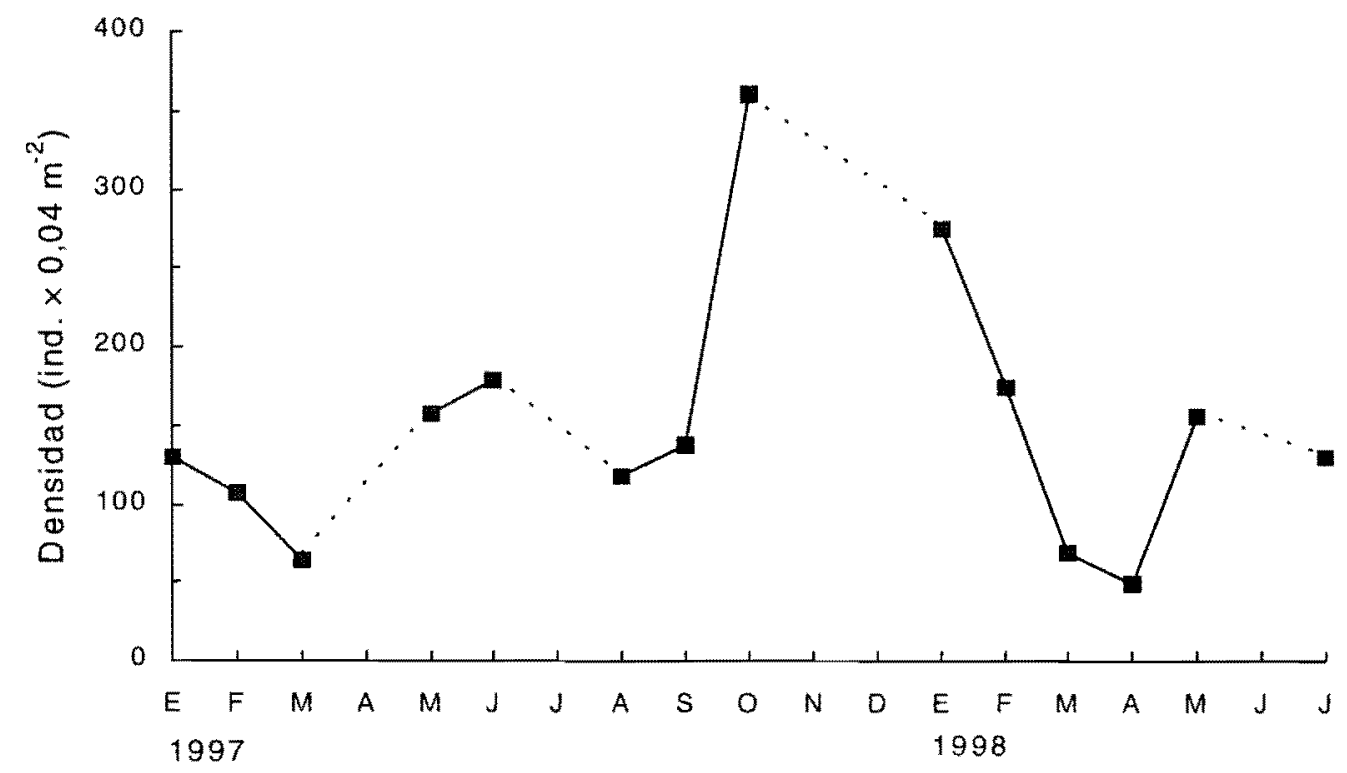

Figura 3. Fluctuaciones mensuales de la densidad media del macrozoobentos durante "El Niño 1997-98" en Catarindo, Mollendo.

muy bajos, en este grupo la mayor biomasa fue de Amphipoda (en la mayoría de la estaciones), Pagurus sp. (durante el invierno de 1997) y un Natantia indeterminado (en el verano de 1998).

\section{La diversidad}

Los valores del índice de diversidad (Shannon y Weaver) fluctuaron entre 1,5 a 3,2 bits en mayo de 1997 y abril de 1998 respectivamente (Fig. 7), mostraron un

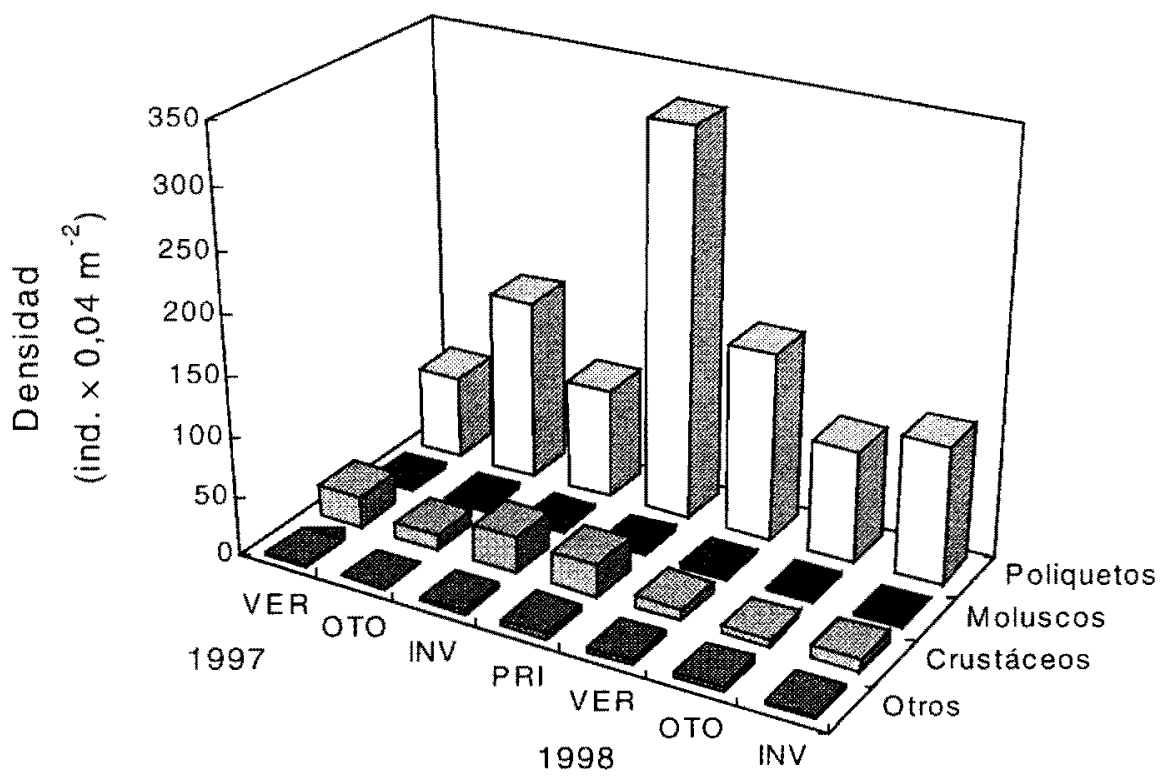

Figura 4. Fluctuaciones estacionales de la densidad del macrozoobentos durante "El Niño 1997-98" en Catarindo, Mollendo. 


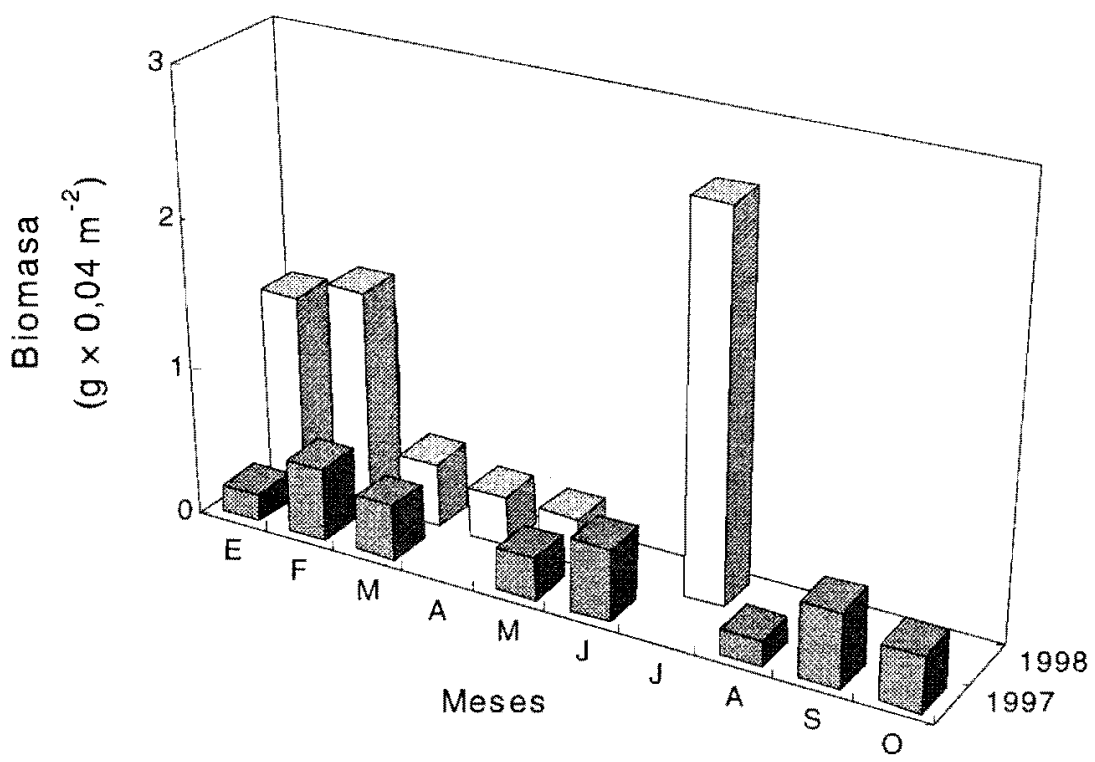

Figura 5. Biomasa media del macrozoobentos durante "El Niño 1997-98" en Catarindo, Mollendo.

incremento en los meses de febrero ( 2,88 bits) y agosto (2,64 bits) de 1997, presentando un tercer incremento, más pronunciado, en abril de 1998 (3,22 bits); incrementos de la diversidad que correspondieron a las estaciones de verano e invierno de 1997 y el otoño de 1998 , mostrando un comportamiento parecido a los incrementos de la temperatura producidos por efectos de $\mathrm{EN}$.

\section{DISCUSIÓN}

La temperatura superficial del mar en la bahía de Catarindo durante el fenómeno "El

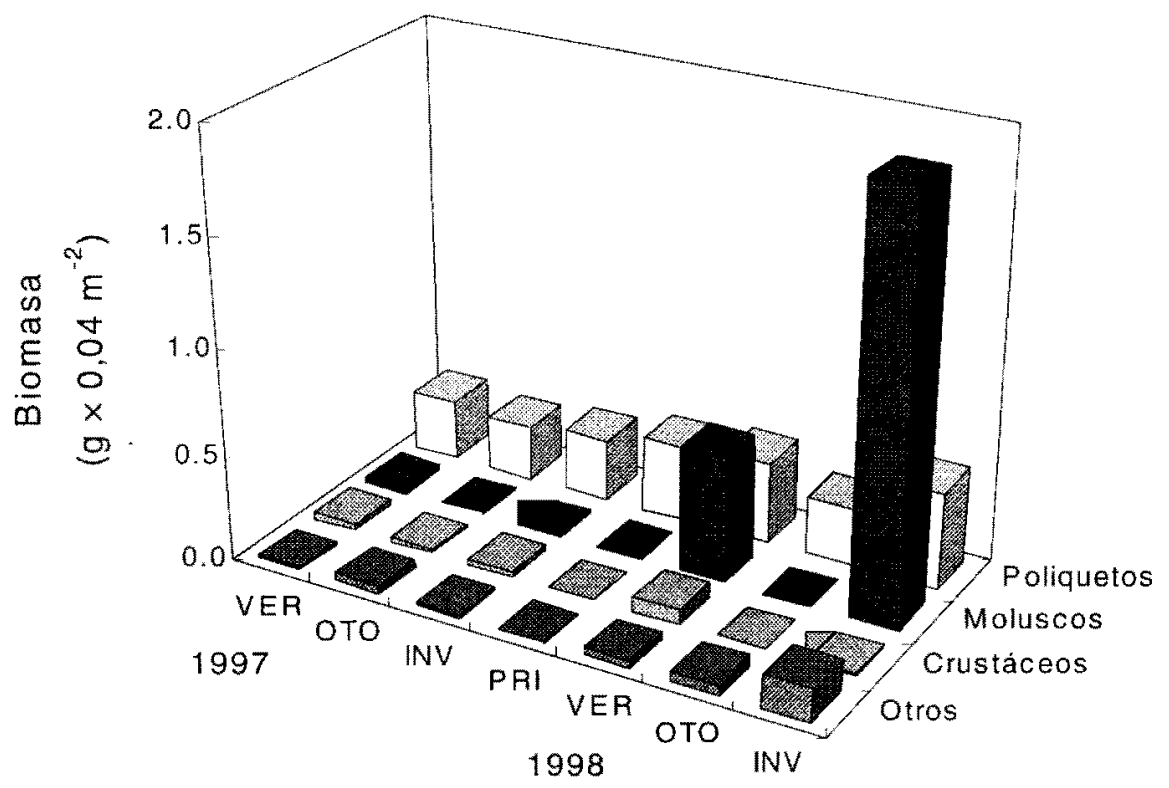

Figura 6. Comportamiento estacional de la biomasa del macrozoobentos. "El Niño 1997-98" en Catarindo, Moliendo. 


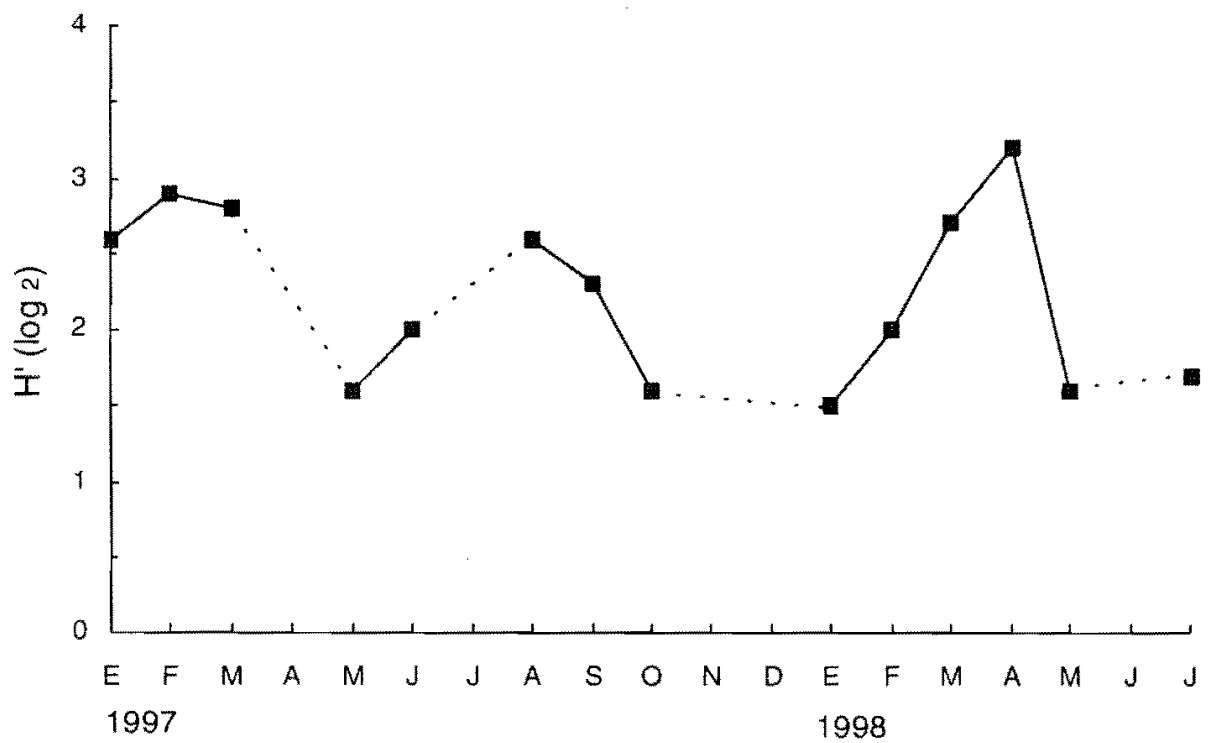

Figura 7. Fluctuaciones mensuales del índice H' en el macrozoobentos. "El Niño 1997-98" en Catarindo, Mollendo.

Niño 1997-98", se caracterizó por presentar dos fases durante este período: la primera fase producida en el invierno de 1997, que alcanzó anomalias hasta $+3,7^{\circ} \mathrm{C}$ respecto al promedio patrón, mientras que la segunda fase en el verano de 1998 las anomalías llegaron hasta $4,9^{\circ} \mathrm{C}$. Este comportamiento de la TSM durante el fenómeno "El Niño 1997-98", correspondería a un fenómeno EN de intensidad fuerte según la clasificación de Quinn et al. (1987) y según Espino (1997) estaría dentro de los eventos de El Niño de series frías, que presentan un pico máximo en otoño-inviemo y otro de menor intensidad durante la primavera-verano siguiente; sin embargo, en este evento el segundo pico se presentó con más intensidad que el primero.

Durante EN 1997-98, en Catarindo se registró un progresivo incremento de la densidad del macrozoobentos a partir de marzo de 1997; incremento que probablemente estaría relacionado con el aumento de las concentraciones de oxígeno disuelto en el fondo, por efecto del incremento de la temperatura durante la primera fase del fenómeno EN, de manera similar a 10 establecido por Tarazona et al. (1985) para la bahía de Ancón durante la primera fase de EN 1982-83. De otro lado, de agosto a octubre de 1997, Flores ( 1997) registró una disminución de la densidad del bentos para la zona de Ilo, coincidiendo con lo registrado en Catarindo en agosto en el que se observó una pequeña disminución de la densidad del macrozoobentos, asociado a un relajamiento de las condiciones térmicas de estos meses.

En este evento cálido también se ha producido un aumento de la densidad de los moluscos y crustáceos en el otoño-inviemo 1998, incrementándose la biomasa del macrozoobentos, por una recolonización de la fauna bentónica cuando aparecen condiciones más favorables como lo menciona Leppäkoski, 1975 (citado por Tarazona et al., 1985). El incremento de la depredación habría influenciado en una disminución de la densidad durante la segunda fase de EN, de manera similar a lo afirmado por Artnz y Valdivia (1985).

Tarazona et al. (1985) y Salzwedel (1998) registraron un incremento del número de especies y la diversidad durante EN 1982-83; como en Catarindo, se ha observado un mayor número de especies, así como un incremento 
de la densidad durante EN 1997-98, comparados con los valores encontrados en 1996 para esta misma zona.

Agradecimientos: Al Instituto de Investigación y Desarrollo Hidrobiológico (INDEHI) y a la Red de Impacto Biológico de los Eventos "El Niño" (RIBEN), por el apoyo económico. Al Blgo. Luis Ortiz por su colaboración en el análisis de las muestras. Al personal de la Univ. Nac. de San Agustín (UNSA) por su apoyo en los muestreos de campo.

\section{LITERATURA CITADA}

Arntz, W.: A. Flores: M. Maldonado y G. Carbajal. 1985. Cambios de los factores ambientales. macrobentos y bacterias filamentosas en la zona de minimo oxígeno frente al Pcrú durante "El Niño" 1982-1983. En: W. Amtz; A. Landa y J. Tarazona (eds.). "El Niño", su impacto en la fauna marina Bol. Inst. Mar Perit-Callao Vol. Extraor: $65-77$.

Arntz, W. y J. Valdivia. 1985. Visión integral del problema "El Niño": Introducción. $E n$ : W. Arntz; A. Landa y J. Tarazona (eds.). "El
Niño". su impacto en la fauna marina. Bot Inst. Mar Perí-Callao Vol. Extraor.: 5-10.

Espino, M. 1997. El Niño 1997-? y los recursos pesqueros: una propuesta de análisis. Inf. linst. Mar Peri-Callao (66): 27-44.

Flores, L. 1997. Efectos del fenómeno "El Niño" sobrc el macrozoobentos de áreas someras del sublitoral de la bahía de llo 1995-1997. Seminario Taller Impacto Biológico de los eventos "El Niño". Lima. Perú. Libro de Resimenes.

Quinn, W.H.; V.T. Neal \& S.E. Antunez de Mayolo. 1987. El Niño ocurrences over the past four and half conturies. J. Geophys. Res. 92 (C13): 14449-14461.

Salzwedel, H.; L. Flores: E. Ch. De Flores; A. Zalra y G. Carbajal. 1988. Macrozoobentos del sublitoral peruano antes, durante y después de El Niño 1982-1983. En: H. Salzwedel y A. Landa (eds.). Recursos y dinámica del ecosistema de afloramiento peruano. Bol list. Mar Peri-Callao Vol. Extraor.: 77-97.

Tarazona, J.: W. Arntz; E. Canahuire: Z. Ayala y A. Robles. 1985. Modificaciones producidas durante "El Niño" en la infauna bentónica de áreas someras del ecosistema de afloramiento peruano. En: W. Amtz; A. Landa y J. Tarazona (eds.). "El Niño", su impacto en la tauna marina. Bol. Inst. Mar Perí-Callao Vol. Exiraor: $55-63$. 